Brazilian Journal

of Chemical

ISSN 0104-6632

Printed in Brazil

Engineering

www.scielo.br/bjce

Vol. 35, No. 03, pp. 1153-1162, July - September, 2018

dx.doi.org/10.1590/0104-6632.20180353s20170432

\title{
THERMODYNAMIC PROPERTIES AND PITZER PARAMETER DETERMINATION FOR ORTHOPHOSPHORIC ACID FROM FREEZING POINT AND ISOPIESTIC MEASUREMENT DATA
}

\author{
Z. Bakher ${ }^{1, *}$ and M. Kaddami ${ }^{1}$ \\ ${ }^{1}$ Laboratory "Physical Chemistry of Processes and Materials" Faculty of Science \\ and Technology, University Hassan 1, Settat, Morocco \\ (Submitted: August 14, 2017; Revised: October 4, 2017; Accepted: October 5, 2017)
}

\begin{abstract}
The freezing depression points of aqueous phosphoric acid have been determined using a method based on measurement of solution conductivity. The osmotic coefficient for freezing point lowering was calculated by the condition of solid-liquid equilibrium and by the equation proposed by Bjerrum (1918). A calculation method is presented in this study to evaluate the ion interaction parameters for the Pitzer model from freezing point and isopiestic molalities of aqueous phosphoric acid solution. The model of Chen, Bromely and the Three-Characteristic Parameter Correlation (TCPC) are also used to model this system. The isopiestic molality values from literature data are used to optimize these models. Using these parameters, we were able to estimate thermodynamic properties: osmotic coefficient, mean activity coefficient and water activity for the $\mathrm{H}_{3} \mathrm{PO}_{4}-\mathrm{H}_{2} \mathrm{O}$ system, and contribution to a better understanding of the thermodynamic behaviour of the aqueous system containing phosphoric acid.
\end{abstract}

Keywords: Phosphoric acid, Pitzer parameters, Water activity, Activity coefficient, Osmotic coefficient.

\section{INTRODUCTION}

Phosphoric acid is one of the strategic elements in the agriculture and pharmaceutical domain. In the literature, there are several different studies predicting all the parameters of the $\mathrm{H}_{3} \mathrm{PO}_{4}-\mathrm{H}_{2} \mathrm{O}$ system, although they were only realized at $298.15 \mathrm{~K}$ and done on water vapor pressure.

The thermodynamic properties of phosphoric acid are of crucial importance in industrial processes such as crystallization, reactors and chemistry reactions. The thermodynamic model proposed by Pitzer was used in this study to predict thermodynamic properties based on freezing point depression experimental results. In general, the use of the Pitzer model is based on the determination of parameters from experimental data, for example: the determination of water activity in the ternary system $\mathrm{KI}-\mathrm{KNO}_{3}-\mathrm{H}_{2} \mathrm{O}$ at $298.15 \mathrm{~K}$ using an electronic hydrometer by Galleguillos et al. (2003), determination of activity coefficients of electrolytes in the ternary system $\mathrm{NaCl}-\mathrm{Na}_{2} \mathrm{SO}_{4}-\mathrm{H}_{2} \mathrm{O}$ from potential difference measurements at 298.15, 303.15 and $308.15 \mathrm{~K}$ by Sirbu et al. (2011) and osmotic and activity coefficients of dilute aqueous solutions of unsymmetrical tetraalkylammonium Iodides at $298.15 \mathrm{~K}$ using the isopiestic method by Amado-Gonzalez et al. (2012).

*Corresponding author. E-mail address: z.bakher@uhp.ac.ma 
There are also other thermodynamic models widely used to determine the thermodynamic properties of electrolytic solutions. Bromely (1973) presented a method for calculating the osmotic coefficient and the activity coefficient. He presented the values of the parameters used in this equation at $298.15 \mathrm{~K}$ to determine the properties of various electrolyte systems. This model has been used in several fields, for example in the work of Vicum et al. (2003), where the Bromley model was used for the non-stoichiometric precipitation of barium sulfate, $\mathrm{BaSO}_{4}$. Chen et al. (1982) proposed a model to calculate the activity coefficient with long-range and short-range contributions. This model successfully correlated experimental data at $298.15 \mathrm{~K}$, for example in the work of Taghi et al. (2003), who applied the Chen model to correlate experimental data of the osmotic coefficient and density of non-aqueous systems. Recently, the Three-Characteristic Parameter Correlation (TCPC) model proposed by $\mathrm{Ge}$ et al. (2007) was used to correlate experimental data of several aqueous and non-aqueous systems.

In the case of aqueous phosphoric acid solution, the work of Pitzer et al. (1976) was an important effort to predict the thermodynamic parameters of phosphoric acid at $298.15 \mathrm{~K}$ up to 6 mol. $\mathrm{kg}^{-1}$ based on the statisticalmechanical equations. Their work employed isopiestic results coupled with electromotive force (EMF). Holmes et al. (1999) determined experimentally the isopiestic molalities of aqueous solutions of phosphoric acid at high temperature in the range of 383.15 to $523.15 \mathrm{~K}$. The recent study proposed by Yang et al. (2016) presents experimental values of water activity at $298.15 \mathrm{~K}$ using the isopiestic method.

The objective of this work is to present new experimental values of freezing depression points up to $241.15 \mathrm{~K}$ by using the conductimetric method, thus combining the freezing point and isopiestic data to predict more general and precise thermodynamic properties for the phosphoric acid-water system up to 8 mol. $\mathrm{kg}^{-1}$, with a suggestion for adapting Pitzer's model to any temperature of phosphoric acid solutions, with comparison to the Chen model, Bromley model and Three-Characteristic Parameter Correlation model (TCPC).

\section{EXPERIMENTAL METHODS}

In the present study, the freezing point depression was determined experimentally by using a method based on measurements of conductivity, $\lambda$. In this method, the ice solubility curve is measured at fixed temperature by adding step-by-step phosphoric acid with a known concentration. The saturation by ice is achieved, which generates a variation in the slope of the curve of solution conductivity versus concentration. At this point the freezing temperature and molality are determined (Goundali et al., 2008; Goundali et al., 2007). For example, to determine freezing depression points of the system $\mathrm{H}_{2} \mathrm{O}-\mathrm{A}$, we start with the sample $\mathrm{M}$, Figure 1-B. After each addition, the conductivity of the solution is measured until stability of its value. The curve (A) in Figure 1 (conductivity $=\mathrm{f}$ (volume of water)) obtained for the binary system $\mathrm{H}_{2} \mathrm{O}$-A presents a break at phase change when an invariant equilibrium is analyzed. The operation is repeated until the total determination of the liquidus of the ice.

Figure 2 shows the experimental setup used for the FPD determinations using the conductimetric method.

\section{RESULTS}

Table 1 presents the ice saturation curve obtained for the $\mathrm{H}_{3} \mathrm{PO}_{4}-\mathrm{H}_{2} \mathrm{O}$ system in the range of temperature from 241.15 to $268.15 \mathrm{~K}$ with an estimated standard temperature uncertainty of $\pm 0.1 \mathrm{~K}$. The temperature control was performed by a VWR Model 1197P thermostat (USA). Water was distilled twice with
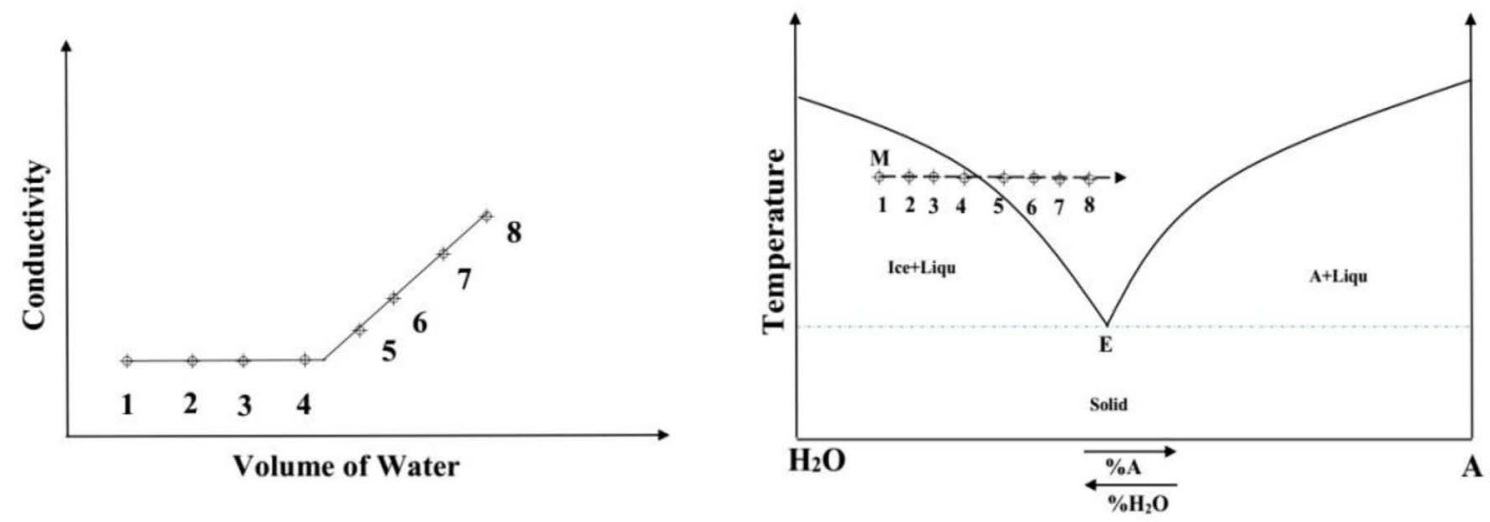

Figure 1. Conductivity study variation of the isothermal dilution of mixture $\mathrm{M}$ in the binary system $\mathrm{H}_{2} \mathrm{O}-\mathrm{A}$ 


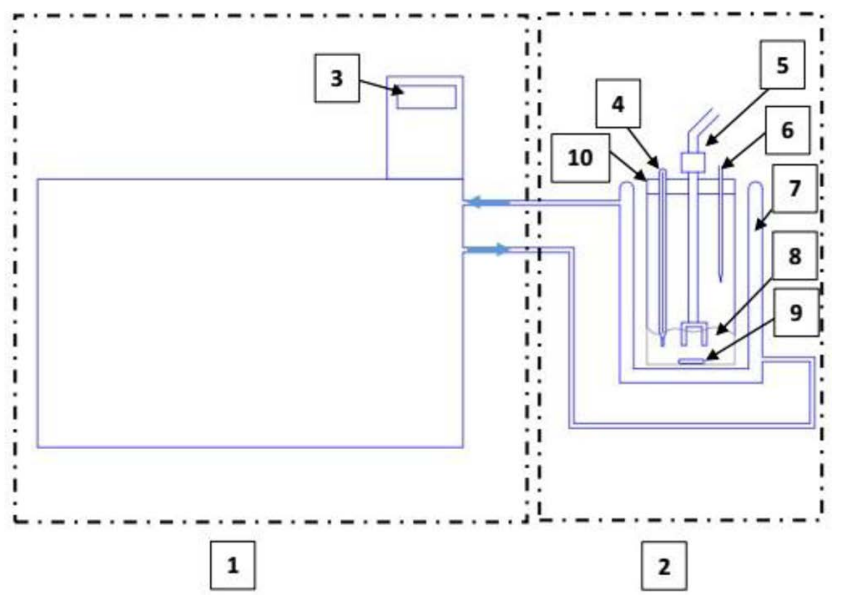

Figure 2. Experimental setup, (1) refrigerator; (2) conductimetric measuring zone; (3) temperature display; (4) thermometer; (5) conductivity meter; (6) capillary water-inlet; (7) thermostatic jacket; (8) aqueous solution; (9) magnetic bar; (10) closure cap.

conductivity on the order of $6 \mu \mathrm{S}$ at $291.15 \mathrm{~K}$. Two products were used to ensure the reliability of the experimental results, phosphoric acid with $85 \%$ concentration in water that presents $99.99 \%$ purity and phosphorus pentoxide with purity $99 \%$. (SigmaAldrich) The concentration of phosphoric acid was verified using titration with sodium hydroxide.

In Figure 3, our experimental freezing depression values and those of Lide (2003-2004) and Jones et al. (1907) are presented and compared. This figure shows that the data of Jones et al. (1907) have a large deviation and below $267.6 \mathrm{~K}$ the difference between the values is significant.

The isopiestic molalities of aqueous phosphoric acid solutions have been measured by Holmes et al. (1999) using $\mathrm{NaCl}$ for the reference solution in the range of temperature from 383.15 to $523.15 \mathrm{~K}$ for molality up to $10 \mathrm{~mol} \cdot \mathrm{kg}^{-1}$. Table 2 presents the number of points used to model phosphoric acid's parameters.

In the presence of phosphoric acid in solution, the equilibrium between ice and water liquid is described by:

$$
\mathrm{H}_{2} \mathrm{O}(\text { solid }) \leftrightarrow \mathrm{H}_{2} \mathrm{O}(\text { liquid })
$$

Below the temperature $273.15 \mathrm{~K}$ the condition for the equilibrium is:

$\mu\left(H_{2} O\right)_{l}=\mu\left(H_{2} O\right)_{S}^{*}=\mu(T)^{*}{ }_{l}+R T \ln \left(a_{w}\right)$

In eq $2, \mu$ designates the chemical potential and the asterisk (*) the pure phase, $a_{w}$ represents the activity of water. Following eq. 3, one can calculate directly values of water activity from the experimental data of freezing point based on the Gibbs-Duhem equation.
Table 1. Experimental results for freezing point depression.

\begin{tabular}{|c|c|c|c|c|}
\hline $\mathrm{m}\left[\mathrm{mol} \cdot \mathrm{kg}^{-1}\right]$ & $\Delta[\mathrm{K}]^{\mathrm{b}}$ & $\mathrm{T}[\mathrm{K}]^{\mathrm{a}}$ & $\Phi_{\exp } \mathrm{c}$ & $\phi_{\text {Bjerrum }}$ \\
\hline $0.0400^{\mathrm{d}}$ & 0.1 & 273.05 & 0.6722 & 0.6728 \\
\hline $0.1100^{\mathrm{d}}$ & 0.25 & 272.9 & 0.6112 & 0.6116 \\
\hline $0.2617^{\mathrm{d}}$ & 0.6 & 272.55 & 0.6167 & 0.6171 \\
\hline $0.5371^{\mathrm{d}}$ & 1.2 & 271.95 & 0.6011 & 0.6013 \\
\hline $0.8874^{\mathrm{d}}$ & 1.8 & 271.35 & 0.5459 & 0.5459 \\
\hline $1.5248^{\mathrm{d}}$ & 3.6 & 269.55 & 0.6359 & 0.6353 \\
\hline $1.8008^{\mathrm{d}}$ & 4 & 269.15 & 0.5984 & 0.5977 \\
\hline $2.1750^{\mathrm{e}}$ & 5 & 268.15 & 0.6418 & 0.6186 \\
\hline $2.6153^{\mathrm{d}}$ & 6.5 & 266.65 & 0.6704 & 0.6688 \\
\hline $3.2020^{\mathrm{e}}$ & 9 & 264.15 & 0.7596 & 0.7564 \\
\hline $4.0876^{\mathrm{d}}$ & 12 & 261.15 & 0.7939 & 0.7900 \\
\hline $4.5847^{\mathrm{d}}$ & 14 & 259.15 & 0.8266 & 0.8217 \\
\hline $5.1480^{\mathrm{e}}$ & 16 & 257.15 & 0.8499 & 0.8364 \\
\hline $6.0690^{\mathrm{e}}$ & 20 & 253.15 & 0.8898 & 0.8868 \\
\hline $7.1770^{\mathrm{e}}$ & 25 & 248.15 & 0.9441 & 0.9374 \\
\hline $7.8190^{\mathrm{e}}$ & 28 & 245.15 & 1.0477 & 0.9637 \\
\hline $8.0380^{\mathrm{d}}$ & 30 & 243.15 & 1.0192 & 1.0069 \\
\hline $8.3831^{\mathrm{d}}$ & 32 & 241.15 & 1.0405 & 1.0272 \\
\hline
\end{tabular}

${ }^{a}$ Estimated standard uncertainties $\mathrm{u}$ are $: \mathrm{u}(\mathrm{T})=0.1^{\circ} \mathrm{K}, \mathrm{u}(\mathrm{m})=0.005$, $\mathrm{u}(\phi)=0.0125$

${ }^{\mathrm{b}}$ Freezing point depression $\left(\Delta=273.15-\mathrm{T}^{\mathrm{f}}\right)$,

${ }^{c}$ Osmotic coefficient calculated by eq 7 ,

${ }^{\mathrm{d}}$ using Phosphorus pentoxide,

${ }^{\mathrm{e}}$ using Phosphoric acid.

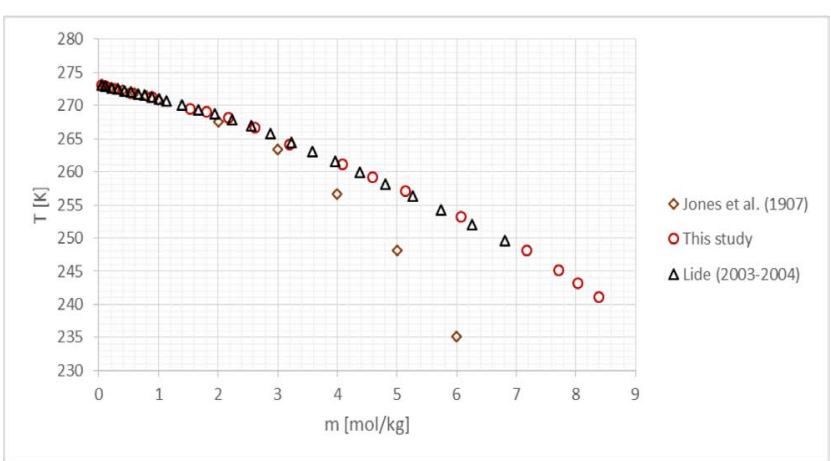

Figure 3. Experimental data for phosphoric acid freezing point depression.

$$
\begin{aligned}
& \ln \left(a_{w}\right)=\frac{-\Delta H^{*}}{R}\left[\frac{1}{T^{f}}-\frac{1}{273.15}\right]- \\
& \frac{\Delta C_{p}}{R}\left[\frac{\left(T^{f}-273.15\right)}{T^{f}}-\ln \left(\frac{T^{f}}{273.15}\right)\right]
\end{aligned}
$$

In the present calculations, the following values were used in this equation: the enthalpy of fusion for pure water $\Delta H^{*}=6009.5 \mathrm{~J} \mathrm{~mol}^{-1}$, the universal

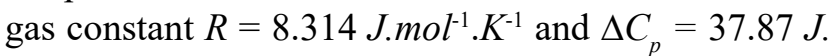
$\mathrm{mol}^{-1}$. $K$ (Osborne, 1939; Osborne et al., 1939). The heat capacity value was used by Hassan et al. (2014) to calculate Pitzer's parameters for $\mathrm{NaCl}$ and $\mathrm{KCl}$ from 
the freezing point and by Arrad et al. (2015) in the case of ferric nitrate up to the temperature $248.15 \mathrm{~K}$.

The osmotic coefficient $\phi$ is defined by the ratio $\pi$ (real)/ $\pi($ ideal), where $\pi$ is the osmotic pressure:

$$
\pi=\frac{R T}{\vartheta_{S}} \ln \left(a_{S}\right)
$$

where $\vartheta_{s}$ is the molar volume of solvent. Therefore, the expression of the osmotic coefficient becomes:

$$
\phi=\frac{\pi(\text { real })}{\pi(\text { ideal })}=\frac{\ln \left(a_{S}^{\text {real }}\right)}{\ln \left(a_{S}^{\text {ideal }}\right)}
$$

In the case of an electrolyte solution, where one molecule of acid MX dissociates into $v$ ions, the ideal solution activity of the solvent (water in this case) is:

$$
\ln \left(a_{W}^{\text {ideal }}\right)=\frac{-M_{S}}{1000} \mathrm{~V} m_{M X}
$$

By using equations 5 and 6 , the osmotic coefficient equation in the real solution becomes:

$$
\phi=\left(\frac{-1000}{M_{S} \mathrm{~V} m_{M X}}\right) \ln \left(a_{W}^{\text {real }}\right)
$$

The activity coefficient for a real solution is calculated using Equation 3.

The other method to calculate the osmotic coefficient from the freezing point lowering was presented by Randal (1923):

$$
j=1-\frac{\theta}{\mathrm{V} \delta m}
$$

A quantity $\phi$ identical in value with (1-j) was called the osmotic coefficient by Bjerrum (1918); the function $\mathrm{j}$ is a property of the solvent:

$$
\phi=\frac{\theta}{\mathrm{V} \delta m}
$$

where $v$ is the number of molecules formed per molecule of solute, $\theta$ is the freezing point lowering, $\delta$ is a constant $=1.858$ (Randall, 1923) and $\mathrm{m}$ is the molality.

The application of equation 7 in our study is represented by:

$$
\phi=\frac{-1000}{v \cdot M_{H 20} \sum_{i=1}^{n} m_{i}} \ln \left(a_{w}\right)
$$

where $m_{i}$ is molality of species [mol. $\left.\mathrm{kg}^{-1}\right]$ in the solution, the molar mass of water $\mathrm{M}_{\mathrm{H} 20}=18.01528 \mathrm{~g}_{\mathrm{mol}} \mathrm{m}^{-1}$ with $v=\left(v^{+}+v^{-}\right)$. The results of application of equations 9 and 10 are presented in Table 1 .

\section{THERMODYNAMIC MODELING}

\section{Pitzer model}

The Pitzer model was applied for the treatment of non-ideality and in the case of 1-1 electrolyte the osmotic coefficient $\phi$ of the solution and mean activity coefficient $\gamma^{ \pm}$of the electrolyte can be written as:

$$
\begin{aligned}
\ln \left(\gamma_{M X}^{ \pm}\right) & =\left|Z^{+} Z^{-}\right| f^{\gamma}+m\left(\frac{2 v^{+} v^{-}}{v}\right) B_{M X}^{\gamma} \\
& +m^{2}\left[\frac{2\left(v^{+} v^{-}\right)^{3} / 2}{v}\right] C_{M X}^{\gamma} \\
\phi-1 & =\left|Z^{+} Z^{-}\right| f^{\phi}+m\left(\frac{2 v^{+} v^{-}}{v}\right) B_{M X}^{\phi} \\
& +m^{2}\left[\frac{2\left(v^{+} v^{-}\right)^{3} / 2}{v}\right] C_{M X}^{\phi}
\end{aligned}
$$

where:

$$
\begin{gathered}
f^{\gamma}=-A^{D-H}\left[\frac{\sqrt{I}}{1+b \sqrt{I}}+\frac{2}{b} \ln (1+b \sqrt{I})\right] \\
B_{M X}^{\gamma}=2 \beta_{M X}^{0}+\frac{2 \beta_{M X}^{1}}{a^{2} \sqrt{I}}\left[1-\left(1+\alpha \sqrt{I}-\frac{\alpha^{2} \sqrt{I}}{2}\right) e^{-a \sqrt{I}}\right] \\
C_{M X}^{\gamma}=\frac{3}{2} C_{M X}^{\phi} \\
f^{\phi}=-A^{D-H}\left[\frac{\sqrt{I}}{1+b \sqrt{I}}\right] \\
B_{M X}^{\phi}=2 \beta_{M X}^{0}+\frac{2 \beta_{M X}^{1}}{\alpha^{2} \sqrt{I}}\left[e^{-\alpha \sqrt{I}}\right]
\end{gathered}
$$

$$
A^{D-H}=\frac{1}{3} \sqrt{2 \pi N_{0} d_{1}}\left(\frac{e^{2}}{4 \varepsilon D K T}\right)^{\frac{3}{2}}
$$

where $v^{+}$and $v^{-}$are the numbers of $\mathrm{M}$ and $\mathrm{X}$ ions in the formula, $Z^{+}$and $Z^{-}$are their respective charges, $\mathrm{m}$ is the conventional molality, $A^{D-H}$ is the Debye-Hückel constant, $d_{l}$ is water density and $\varepsilon$ is permittivity of vacuum, $D$ the dielectric permeability of pure water at temperature T [K], $N_{0}$ is Avogadro's number, $K$ is the Boltzmann constant, the value of $A^{D-H}$ is $0.392 \mathrm{~kg}^{1 / 2}$. $\mathrm{mol}^{-1 / 2}$ at $298.15 \mathrm{~K}$.

The Pitzer values of two parameters $a$ and $b$ are 2.0 and 1.2 , respectively. $I$ is the stoichiometric ionic strength of the solution $[\mathrm{mol} / \mathrm{kg}]$. 


\section{Bromley model}

The equation of the Bromley model for the calculation of the osmotic coefficient can be written as:

$$
\begin{aligned}
& 1-\phi=2.303 A_{\gamma}\left|Z^{+} Z^{-}\right| \frac{\sqrt{I}}{3} \delta(\rho \sqrt{I}) \\
& -2.303(0.06+0.6 B(T))\left|Z^{+} Z^{-}\right| \frac{I}{2} \psi(a I) \\
& -2.303 B(T) \frac{I}{2}
\end{aligned}
$$

where:

$$
\begin{gathered}
a=\frac{1.5}{\left|Z^{+} Z^{-}\right|} \\
\delta(\rho \sqrt{I})=\frac{3}{\rho \sqrt{I}}\left\{1+\rho \sqrt{I}-\frac{1}{1+\rho \sqrt{I}}-2 \ln (1+\rho \sqrt{I})\right\} \\
\psi(a I)=\frac{2}{a I}\left[\frac{1+2 a I}{(1+a I)^{2}}-\frac{\ln (1+a I)}{a I}\right]
\end{gathered}
$$

where $A_{\gamma}$ is the Debye-Hückel constant on a $\log \mathrm{e}$ basis at temperature $\mathrm{T}[\mathrm{K}], \rho$ is a constant related to the distance of closest approach; in this case the value of $\rho=1.0$, Iis the ionic strength and $B(T)$ is Bromley's parameter.

\section{Chen model}

Chen et al.(1982) proposed a model for calculating the activity coefficient based on long-range and shortrange contributions:

$$
\ln f_{ \pm}=\ln f_{ \pm}^{L R}+\ln f_{ \pm}^{S R}
$$

where $f_{ \pm}$is the activity coefficient based on mole fraction, LR and SR refer to the long-range and shortrange contributions.

The equation for short-range can be written as:

$$
\ln f_{ \pm}^{L R}=\frac{1}{v}\left(v_{C} \ln f_{+}^{L R}+v_{a} \ln f_{-}^{L R}\right)
$$

with:

$$
\begin{aligned}
& \ln f_{+}^{L R}=\frac{x_{m}^{2} \tau_{c a, m} F_{c m}}{\left(x_{c} F_{c m}+x_{a} F_{c m}+x_{m}\right)^{2}}- \\
& \frac{Z_{-} x_{a} \tau_{m, c a} x_{m} F_{m a}}{\left(x_{a}+x_{m} F_{m a}\right)^{2}}+ \\
& \frac{Z_{+} x_{m} \tau_{m, c a} F_{m c}}{x_{a}+x_{m} F_{m a}}-Z_{+} \tau_{m, c a}-F_{c m} \tau_{c a, m}
\end{aligned}
$$

$$
\begin{aligned}
\ln f_{-}^{L R} & =\frac{x_{m}^{2} \tau_{c a, m} F_{a m}}{\left(x_{c} F_{c m}+x_{a} F_{a m}+x_{m}\right)^{2}} \\
& -\frac{Z+x_{c} \tau_{m, c a} x_{m} F_{m c}}{\left(x_{a}+x_{m} F_{m a}\right)^{2}} \\
& +\frac{Z-x_{m} \tau_{m, c a} F_{m a}}{x_{c}+x_{m} F_{m a}} \\
& -Z_{-} \tau_{m, c a}-F_{a m} \tau_{c a, m}
\end{aligned}
$$

The mole fraction $x_{i}$ as a function of molality $m$ is written as:

$$
x_{i}=\frac{v_{i} m}{v m+\frac{1000}{M_{H 2 O}}}
$$

where $x_{c}, x_{m}, x_{a}$ : are cation, solvent and anion mole fraction, $\tau_{m, c a}$ and $\tau_{c a, m}$ are Chen parameters, $F_{m c}=F_{m a}$ $=\exp \left(-\alpha \tau_{m, c a}\right)$ and $F_{c m}=F_{a m}=\exp \left(-\alpha \tau_{c a, m}\right)$.

The equation for long-range can be written as:

$$
\begin{aligned}
& \ln f_{ \pm}^{L R}=-\sqrt{\frac{1000}{M_{H 20}}} A^{D-H}\left[\frac{2\left|Z^{+} Z^{-}\right|}{\rho}\right. \\
& \left.\ln \left(1+\rho \sqrt{I_{x}}\right)+\frac{\left|Z^{+} Z^{-}\right| \sqrt{I_{x}-2 I_{x}^{\frac{3}{2}}}}{1+\rho \sqrt{I_{x}}}\right]
\end{aligned}
$$

To make the data uniform, the mean activity coefficient is converted to the molality form using the relationship:

$$
\ln \left(\gamma_{M X}^{ \pm}\right)=\ln f_{ \pm}-\ln \left(1+0.001 M_{H 20} v m\right)
$$

In our case, the determination of the Chen parameters is adjusted with the osmotic coefficient data. Pitzer et al. (1986) presented the long-range solvent equation:

$$
\ln \gamma_{\text {solvent }}^{P D H}=\frac{2 A_{x} I_{x}^{3 / 2}}{1+\rho I_{x}^{3 / 2}}
$$

The short-rang contribution of solvent according to the Chen model is:

$$
\begin{aligned}
& \ln f_{S}^{S R}=x_{c m} \tau_{c a, m}+x_{a m} \tau_{c a, m} \\
& +\frac{Z_{+} x_{c} \tau_{m, c a} x_{a} F_{m c}}{\left(x_{a}+x_{m} F_{m a}\right)^{2}} \\
& +\frac{Z_{-} x_{a} \tau_{m, c a} x_{m} F_{a m} x_{c}}{\left(x_{a}+x_{m} F_{m a}\right)^{2}} \\
& -\frac{x_{c} x_{m} F_{c m} \tau_{c a, m}}{\left(x_{c} F_{c m}+x_{a} F_{c m}+x_{m}\right)^{2}} \\
& -\frac{x_{a} x_{m} F_{a m} \tau_{c a, m}}{\left(x_{c} F_{c m}+x_{a} F_{c m}+x_{m}\right)^{2}}
\end{aligned}
$$


with:

$$
x_{i j}=\frac{x_{i} F_{i j}}{x_{a} F_{a j}+x_{c} F_{c j}+x_{m} F_{j j}}
$$

According to equations 30 and 31 , the osmotic coefficient can be calculated by equation 10 , using the expression $\ln a_{s}=\ln x_{s}$.

\section{Three-Characteristic Parameter Correlation model}

The following equation was proposed for calculation of the osmotic coefficient using the ThreeCharacteristic Parameter Correlation model:

$$
\begin{aligned}
& \ln \left(\gamma_{ \pm}\right)=\left|Z^{+} Z^{-}\right| A^{D-H}\left(\frac{\sqrt{I}}{1+b \sqrt{I}}+\frac{2}{b}\right. \\
& \ln (1+b \sqrt{I}))+\frac{S}{T} \frac{I^{2 n}}{v^{+} v^{-}}
\end{aligned}
$$

The osmotic Coefficient can be calculated by integrating the equation for the mean activity coefficient:

$$
\phi=1+\frac{1}{m} \int_{0}^{m} m d \ln \left(\gamma_{ \pm}\right)
$$

From eqs. 33 and 34, the osmotic coefficient can be written as:

$$
\begin{aligned}
& \phi=1-\left|Z^{+} Z^{-}\right| A^{D-H}\left(\frac{\sqrt{I}}{1+b \sqrt{I}}\right)+ \\
& \frac{S}{T\left(v^{+} v^{-}\right)}\left(\frac{2 n}{2 n-1}\right) I^{2 n}
\end{aligned}
$$

In this equation, $\mathrm{b}, \mathrm{S}$ and $\mathrm{n}$ are the three characteristic parameters: $\mathrm{S}$ is the solvation parameter, $\mathrm{b}$ is the approach parameter representing the closest distance between ions and $\mathrm{n}$ is a distance parameter related to the distance between ion and solvent molecule. Using these parameters the osmotic coefficients of electrolytes in aqueous solution could be estimated.

For all thermodynamic models, the ionic strength of the solution $[\mathrm{mol} / \mathrm{kg}]$, is given as:

$$
I=\frac{1}{2} \sum_{i=1}^{n} m_{i} Z_{i}^{2}
$$

The adjustable parameters $\beta_{M X}^{0}, \beta_{M X}^{1}$ and $C_{M X}^{\phi}$ for Pitzer model, $\tau_{m, c a}$ and $\tau_{c a, m}$ for the Chen model, $B(T)$ for the Bromely model and $b, S, n$ for the ThreeCharacteristic Parameter Correlation model are specific for the phosphoric acid-water system. They have been obtained from least-square fitting of the freezing point and isopiestic data.

\section{RESULTS AND DISCUSSION}

The Pitzer parameters for phosphoric acid-water were determined by using different types of data: solubility and isopiestic molalities. Pitzer's most extensive investigation was done for $\mathrm{NaCl}$. As shown in the works of Sippola (2013) and Sippola et al. (2014) the variation of $\beta_{M X}^{0}, \beta_{M X}^{1}$ and $C_{M X}^{\phi}$ was tested using a temperature dependency in the form $=a+\frac{b}{T}$. In our work the variation of Pitzer's parameter values for phosphoric acid resulted in the following equations:

$$
\begin{gathered}
\beta_{M X}^{0}=a^{0}+\frac{b^{0}}{T}+c^{0} \ln (T) \\
\beta_{M X}^{1}=a^{1}+\frac{b^{1}}{T}+c^{1} T^{2} \\
C_{M X}^{1}=a^{\phi}+\frac{b^{\phi}}{T}+c^{\phi} \ln (T)
\end{gathered}
$$

The parameter variation of the Bromley model as a function of the temperature is:

$$
B(T)=\frac{B_{1}}{T-230}+\frac{B_{2}}{T}+B_{3}+B_{4} \ln (T)
$$

The variations of the Chen parameters as a function of the temperature are:

$$
\begin{gathered}
\tau_{m, c a}=a_{m, c a}+b_{m, c a}\left(\frac{1}{T}-\frac{1}{298.15}\right)+ \\
C_{m, c a}\left\{\left(\frac{298.15-T}{T}\right)+\ln \left(\frac{T}{298+15}\right)\right\} \\
\tau_{c a, m}=a_{c a, m}+b_{c a, m}\left(\frac{1}{T}-\frac{1}{298.15}\right)+ \\
C_{c a, m}\left\{\left(\frac{298.15-T}{T}\right)+\ln \left(\frac{T}{298.15}\right)\right\}
\end{gathered}
$$

In the case of the Three-Characteristic Parameter Correlation model $n$ is a constant, the variation of $\mathrm{S}$ and $\mathrm{b}$ as a function of temperature is:

$$
S(T)=a_{S}+\frac{b_{S}}{T}+C_{S} \ln (T)
$$

$$
b(T)=a_{b}+\frac{b_{b}}{T}+C_{b} \ln (T)
$$

The parameter values were determined using the least-squares method with the objective function of 
eq 45 that minimizes the errors between the osmotic coefficients from the thermodynamic models and the experimental values:

$$
O b=\sum_{i=1}^{n}\left(\phi_{\text {exp }}-\phi_{\text {calc }}\right)^{2}
$$

The Deby-Hückel constant $A_{D-H}$ in the range of temperature $230 \mathrm{~K}$ to $298.15 \mathrm{~K}$ was calculated from the polynomial based on the tabulated values of DebyHückel constant presented by Pitzer et al. (1976) as:

$$
\begin{aligned}
& A^{D-H}=-61.44534 \exp \left(\frac{(T-273.15)}{273.15}\right)+ \\
& 2.864468\left[\exp \left(\frac{(T-273.15)}{273.15}\right)\right]^{2}+ \\
& 183.5379 \ln \left(\frac{T}{273.15}\right)- \\
& 0.6820223(T-273.15)+
\end{aligned}
$$

$0.0007875695\left(T^{2}-273.15^{2}\right)+$

$58.95788\left(\frac{273.15}{T}\right)$

For the range 298.15 to $523.5 \mathrm{~K}$, the Deby-Hückel constant is given in the work of Holmes et al. (1999).

The standard deviation, $\sigma$,was defined as:

$$
\sigma^{T}=\left[\frac{\sum_{i=1}^{n}(\phi \exp -\phi c a l c)^{2}}{N P}\right]^{1 / 2}
$$

where $N P$ represents the number of experimental points at each temperature.

The values of ion-interaction parameters for the thermodynamic models are presented in Table 3.

The variation of $\beta_{M X}^{1}$ for the Pitzer model depends on $a^{1}$ and $b^{1}$ because $c^{1}$ is very small:

$$
\beta_{M X}^{1}=a^{1}+\frac{b^{1}}{T}
$$

Following eq 47, we calculated the standard deviation for each model. Table 4 presents the values for every temperature.

As can be seen from Table 4, the values of standard deviations for fitting the experimental data of osmotic coefficient for the Pitzer model are very low compared to the other models.

Figure 4 presents the objective function for the global treatment of each model.

The comparison between experimental results of freezing depression curve and thermodynamic models is presented in Figure 5. According to Figure 5, the Pitzer model accurately predicts the experimental
Table 2. Number of data points used

\begin{tabular}{lccc}
\hline Range of T $[\mathrm{K}]$ & $\begin{array}{c}\text { Number of } \\
\text { points }\end{array}$ & type of data & references \\
\hline $241.15-273.05$ & 18 & $\mathrm{a}$ & this study \\
$249.57-273.03$ & 26 & $\mathrm{a}$ & $\begin{array}{c}\text { Lide }(2003-2004) \\
\text { Holmes et al. } \\
(1999)\end{array}$ \\
383.15 & 26 & $\mathrm{~b}$ & $\begin{array}{c}\text { Holmes et al. } \\
(1999)\end{array}$ \\
413.15 & 33 & $\mathrm{~b}$ & $\begin{array}{c}\text { Holmes et al. } \\
(1999)\end{array}$ \\
443.15 & 38 & $\mathrm{~b}$ & $\begin{array}{c}\text { Holmes et al. } \\
(1999)\end{array}$ \\
473.15 & 29 & $\mathrm{~b}$ & $\begin{array}{c}\text { Holmes et al. } \\
(1999)\end{array}$ \\
498.15 & 23 & $\mathrm{~b}$ & $\begin{array}{c}\text { Holmes et al. } \\
(1999)\end{array}$ \\
\hline
\end{tabular}

Estimated standard uncertainties for data from Holmes et al(1999) $\mathrm{u}$ are $: \mathrm{u}(\mathrm{T})=0.1^{\circ} \mathrm{K}, \mathrm{u}(\mathrm{m})=0.002$,

a: solubility measurement data

b: isopiestic molalities measurement data.

results, which is why their objective function value remains the lowest (Figure 4), whereas the Chen model diverges after $7.2 \mathrm{~mol} / \mathrm{kg}$.

The Pitzer model presents the lowest value of objective function in the case of the phosphoric acid-water system and was used to calculate the activity coefficient of water, osmotic coefficient and mean activity coefficient at different temperatures.

Figure 5 shows the calculated osmotic coefficient for the phosphoric acid-water system at different temperatures using the Pitzer parameters presented in Table 3.

It is important to calculate the mean activity coefficient $\gamma_{H 3 P O 4}^{ \pm}$at temperatures below $273.15 \mathrm{~K}$. Table 5 presents mean activity coefficient values at selected molalities.

The mean coefficient calculated in Table 5 decreases as a function of temperature in high molality, but the values are almost equal in low molality. This confirms results presented earlier by Holmes et al. (1999).

Calculated water activity coefficients are usually reported in terms of the ionic strength. Figure 6 presents the values of $a_{w}$ at $298.15 \mathrm{~K}$ calculated by equations 11 and 10 using the values of Pitzer parameters presented in Table 3.

The water activity coefficients determined at 298.15 in this study using the values of Pitzer's model, Table 3, predict exactly the same values determined experimentally by Platford (1975), the isopiestic measurements of water activity in recent study by Yang et al. (2016) and results presented by Elmore et al. 
Table 3. Values of thermodynamic models parameters for phosphoric acid in the range 241.15 to $523.15 \mathrm{~K}$

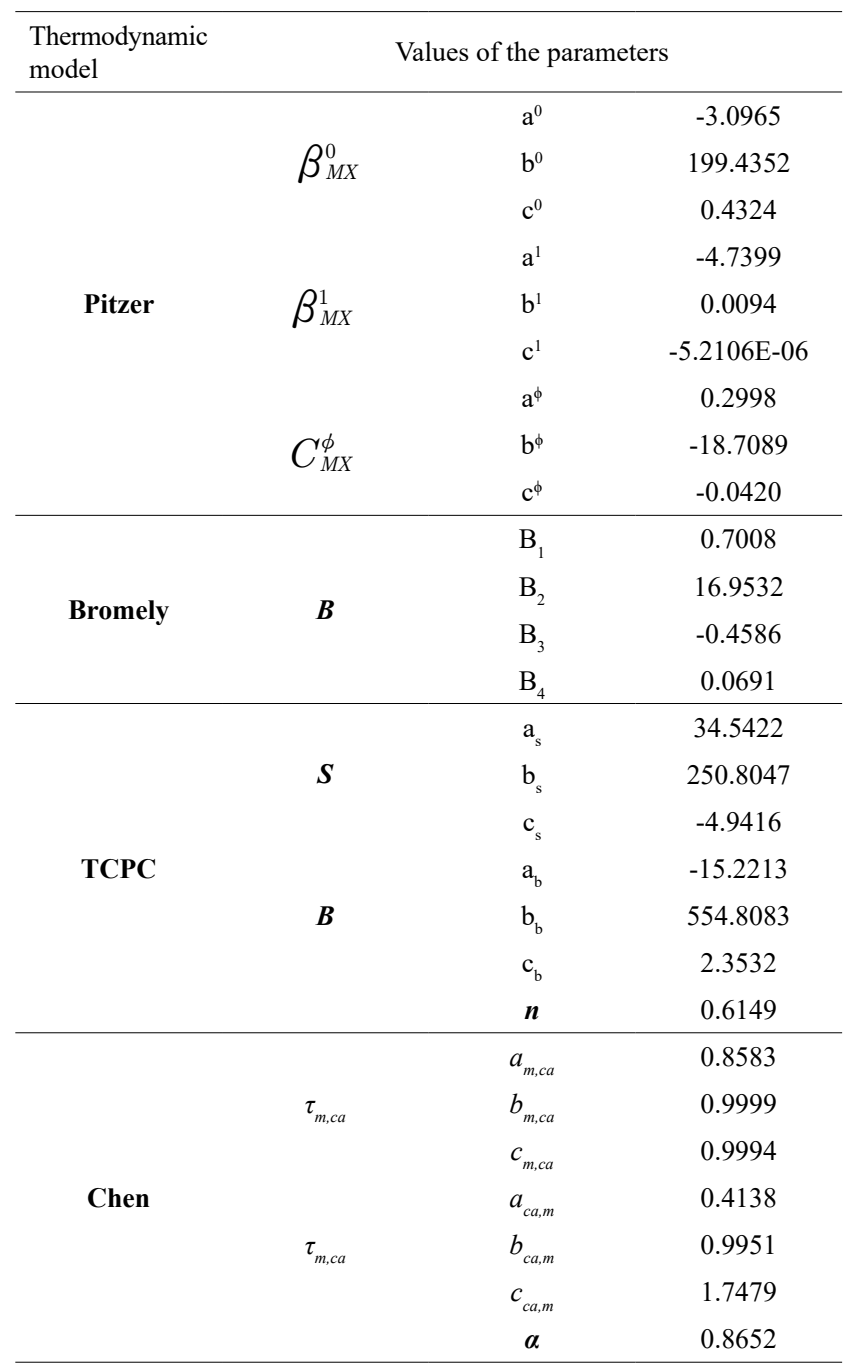

Table 4. Values of the standard deviation at high temperature

\begin{tabular}{cccccc}
\hline \multirow{2}{*}{$\mathrm{T}[\mathrm{K}]$} & \multirow{2}{*}{$\begin{array}{c}\text { Number } \\
\text { of points }\end{array}$} & \multicolumn{5}{c}{$\boldsymbol{\sigma}^{T}$} \\
\cline { 3 - 6 } & & Pitzer & Bromely & TCPC & Chen \\
\hline 383.15 & 26 & 0.0173 & 0.0444 & 0.0456 & 0.0532 \\
413.15 & 33 & 0.0110 & 0.0436 & 0.0420 & 0.0501 \\
443.15 & 38 & 0.0118 & 0.0263 & 0.0364 & 0.0497 \\
473.15 & 29 & 0.0148 & 0.0104 & 0.0385 & 0.0717 \\
498.15 & 23 & 0.0107 & 0.0120 & 0.0247 & 0.0550 \\
523.15 & 29 & 0.0158 & 0.0370 & 0.0360 & 0.0930 \\
\hline
\end{tabular}

(1946), which confirms the Pitzer parameters presented in Table 3.

\section{CONCLUSION}

The present paper reports the results of an experimental freezing point study of aqueous phosphoric acid solutions using a conductimetric method. The model used in this work, that of Pitzer, was compared

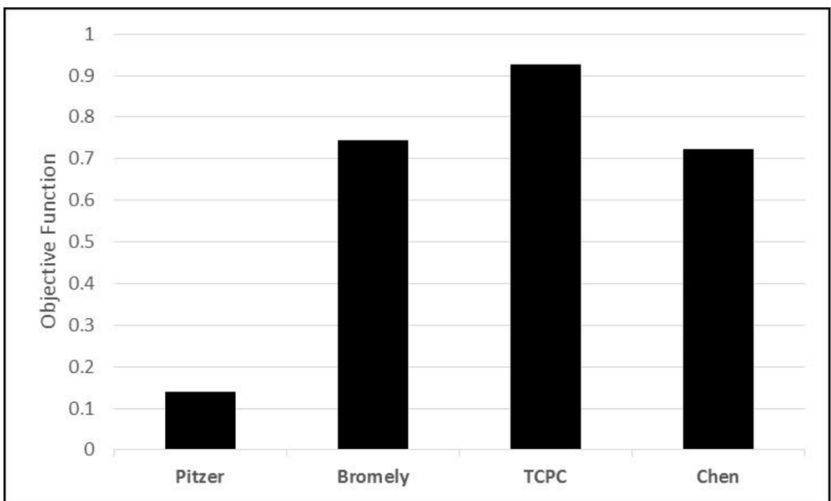

Figure 4. Objective function for each model for the phosphoric acid-water system.

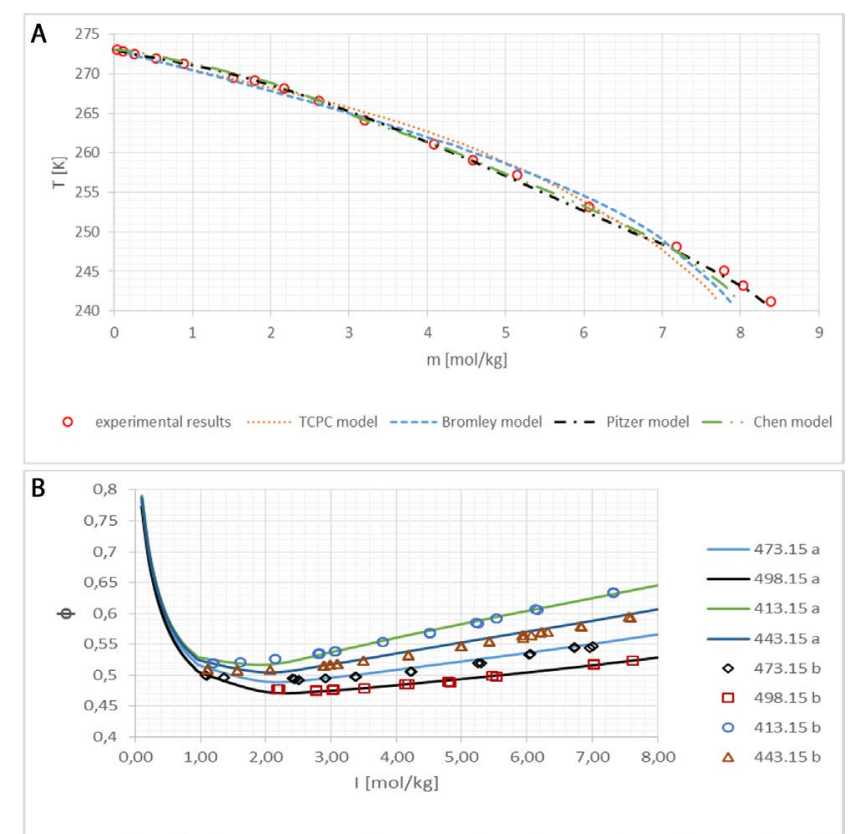

Figure 5. A: Comparison between experimental results and thermodynamic models to predict the freezing depression curve; B: Calculated osmotic coefficient vs. ionic strength at 413.14 to $498.15 \mathrm{~K}$ using Pitzer model: acalculated osmotic coefficient by Pitzer model in this study, bexperimental values of osmotic coefficient.

with 222 points of thermodynamic properties: activity coefficient, mean activity coefficient and osmotic coefficient in the range of temperature from 241.15 to $523.15 \mathrm{~K}$ up to 8 mol. $\mathrm{kg}^{-1}$ for $\mathrm{H}_{3} \mathrm{PO}_{4}-\mathrm{H}_{2} \mathrm{O}$ system. The experimental values related to water activity from the literature confirm the values calculated by the Pitzer model based on the experimental data of freezing point depression, which shows that the use of freezing point depression data for the modeling of electrolyte systems is very interesting.

The form of variation of the Pitzer parameters $\beta_{M X}^{0}$, $\beta_{M X}^{1}$ and $C_{M X}^{\phi}$ presented in this work produces better results compared to the Chen model, Bromley model and 
Table 5. Mean activity coefficient at low temperatures using Pitzer model.

\begin{tabular}{|c|c|c|c|c|c|c|}
\hline \multirow{3}{*}{$\mathrm{m}\left[\mathrm{mol} \cdot \mathrm{kg}^{-1}\right]$} & \multicolumn{6}{|c|}{$\mathrm{T}[\mathrm{K}]$} \\
\hline & 243.15 & 254.3 & 263.03 & 268.15 & 270.14 & 273.15 \\
\hline & \multicolumn{6}{|c|}{$\boldsymbol{\gamma}_{\mathrm{H} 3 \mathrm{PO} 4}^{ \pm}$} \\
\hline 0.1 & 0.5568 & 0.5592 & 0.5593 & 0.5599 & 0.5601 & 0.5603 \\
\hline 0.3 & 0.4235 & 0.4261 & 0.4265 & 0.4273 & 0.4276 & 0.4280 \\
\hline 0.5 & 0.3493 & 0.3517 & 0.3520 & 0.3528 & 0.3531 & 0.3535 \\
\hline 0.7 & 0.3018 & 0.3038 & 0.3040 & 0.3047 & 0.3049 & 0.3053 \\
\hline 0.9 & 0.2690 & 0.2706 & 0.2706 & 0.2711 & 0.2713 & 0.2716 \\
\hline 1 & 0.2452 & 0.2464 & 0.2462 & 0.2466 & 0.2467 & 0.2469 \\
\hline 2 & 0.2273 & 0.2282 & 0.2276 & 0.2279 & 0.2280 & 0.2281 \\
\hline 3 & 0.2135 & 0.2140 & 0.2132 & 0.2133 & 0.2134 & 0.2134 \\
\hline 4 & 0.2027 & 0.2028 & 0.2018 & 0.2017 & 0.2017 & 0.2017 \\
\hline 5 & 0.1941 & 0.1938 & 0.1925 & 0.1924 & 0.1923 & 0.1922 \\
\hline 6 & 0.1613 & 0.1576 & 0.1541 & 0.1527 & 0.1522 & 0.1514 \\
\hline 7 & 0.1603 & 0.1534 & 0.1476 & 0.1451 & 0.1441 & 0.1427 \\
\hline 8 & 0.1664 & 0.1564 & 0.1485 & 0.1450 & 0.1437 & 0.1417 \\
\hline
\end{tabular}

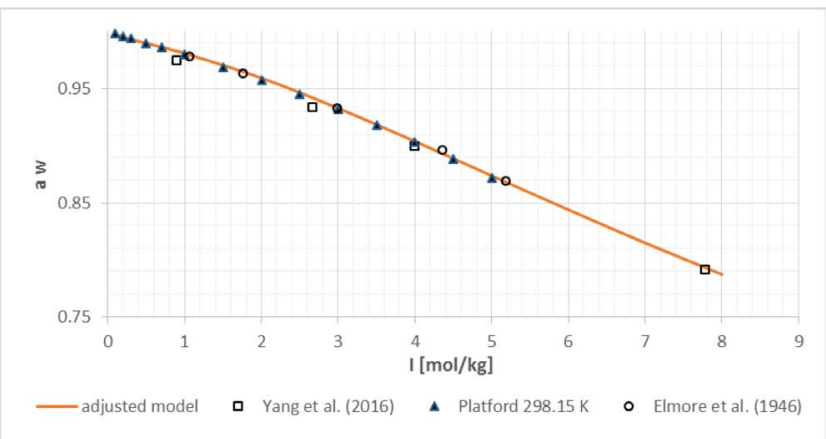

Figure 6. Activity coefficient for water in the $\mathrm{H}_{3} \mathrm{PO}_{4}-\mathrm{H}_{2} \mathrm{O}$ system up to $8 \mathrm{~mol} . \mathrm{kg}^{-1}$ at $298.15 \mathrm{~K}$.

the Three-Characteristic Parameter Correlation model. According to the equations presented in this paper there are two approaches to calculate the osmotic coefficient value from freezing point depression. The first approach is based on the thermodynamic equilibrium condition, whereas the second approach is by direct calculation of the osmotic coefficient, based on the use of the equation proposed by Bjerrum (1918). Both methods resulted in almost the same values with the difference in the third digit after the decimal point, which shows that the Bjerrum equation is recommended to deduce the osmotic coefficient values from the freezing point depression.

\section{NOMENCLAUTURE}

$a_{w} \quad$ Activity of water

$A^{D-H} \quad$ Debye-Hückel parameter $\left(\mathrm{kg}^{\frac{1}{2}} \cdot \mathrm{mol}^{\frac{1}{2}}\right)$

$\mathrm{m} \quad$ Molality $(\mathrm{mol} / \mathrm{kg})$

I Ionic strength of electrolyte

M Molecular weight $(\mathrm{g} / \mathrm{mol})$
T Temperature (K)

FPD Freezing point depression

TCPC Three-Characteristic Parameter Correlation model

b Debye-HUCKEL parameter $\left(\mathrm{kg}^{\frac{1}{2}} \cdot \mathrm{mol}^{\frac{1}{2}}\right)$

\section{Greek letter}

$\mu \quad$ Chemical potential

$\gamma_{M X}^{ \pm}$Activity coefficient of element MX

$\phi \quad$ Osmotic coefficient

$\alpha \quad$ Universal parameter $\left(\mathrm{kg}^{\frac{1}{2}} \cdot \mathrm{mol}^{\frac{1}{2}}\right)$

\section{Sub/Superscripts}

f freezing point

* $\quad$ pure chemical compound

\section{REFERENCES}

Arrad, M., Kaddami, M., Sippola, H., and Taskinen, P., Determination of Pitzer Parameters for Ferric Nitrate from Freezing Point and Solubility of Ice, Journal of Chemical \& Engineering Data, 61(1), 674-678 (2015).

Bjerrum, N., Die Dissoziation der starken Elektrolyte, Z. Electrochem., 24, 321-328 (1918).

Bromley, L.A., Thermodynamic properties of $b$ electrolytes in aqueous solutions, AlChE Journal, 19(2), 313-320 (1973).

Chen, C. C., Britt, H. I., Boston, J. F., and Evans, L. B., Local composition model for excess Gibbs energy of electrolyte systems. Part I: Single solvent, single completely dissociated electrolyte systems. AIChE Journal, 28(4), 588-596 (1982). 
Lide, D.R., CRC, Handbook of Chemistry and Physics, (2003-2004).

Goundali, B. E. and Kaddami, M., The ternary system $\mathrm{H}_{2} \mathrm{O}-\mathrm{Fe}(\mathrm{NO} 3) 3-\mathrm{Co}(\mathrm{NO} 3) 2$ isotherms 0 and $15^{\circ} \mathrm{C}$, Fluid Phase Equilibria, 260(2), 295-299 (2007).

Goundali, B. E. and Kaddami, M., The ternary system: $\mathrm{H}_{2} \mathrm{O}-\mathrm{Fe}(\mathrm{NO} 3) 3-\mathrm{Co}(\mathrm{NO} 3) 2$ isotherms -15 and $-25^{\circ} \mathrm{C}$, Journal of Alloys and Compounds, 460(12), 544-548(2008).

Amado-Gonzalez, E. and Blanco, L. H., Osmotic and Activity Coefficients of Dilute Aqueous Solutions of Unsymmetrical Tetraalkylammonium Iodides at $298.15 \mathrm{~K}$, Journal of Chemical \& Engineering Data, 57(4), 1044(2012).

Elmore, K. L., Mason, C. M., and Christensen, J. H., Activity of Orthophosphoric Acid in Aqueous Solution at $25^{\circ}$ from Vapor Pressure Measurements, Journal of the American Chemical Society, 68(12), 2528-2532 (1946).

Sirbu, F., Iulian, O., Ion, A. C. and Ion, I. Activity Coefficients of Electrolytes in the $\mathrm{NaCl}+\mathrm{Na}_{2} \mathrm{SO}_{4}$ $+\mathrm{H}_{2} \mathrm{O}$ Ternary System from Potential Difference Measurements at $(298.15,303.15$, and 308.15) K, Journal of Chemical \& Engineering Data, 56(12), 4935-4943 (2011).

Hasan, M., Partanen, J. I., Vahteristo, K. P., and Louhi-kultanen, M., Determination of the Pitzer Interaction Parameters at $273.15 \mathrm{~K}$ from the Freezing-Point Data Available for $\mathrm{NaCl}$ and $\mathrm{KCl}$ Solutions, Industrial \& Engineering Chemistry Research, 53(13), 5608-5616 (2014).

Galleguillos, H. R., Graber, T. A., and Taboada, M. E., Activity of Water in the $\mathrm{KI}+\mathrm{KNO}_{3}+\mathrm{H}_{2} \mathrm{O}$ Ternary System at $298.15 \mathrm{~K}$, Journal of Chemical \& Engineering Data, 48(4), 851-855 (2003).

Holmes, H. F., and Mesmer, R. E., Isopiestic Studies of $\mathrm{H}_{3} \mathrm{PO}_{4}$ (aq) at Elevated Temperatures, Journal of Solution Chemistry, 28(4), 327-340 (1999).

Jones, H. C., Getman, F. H., Bassett, H. P. McMaster, L. and Uhler, H. S, Hydrates in Aqueous Solution: Evidence for the Existence of Hydrates in Solution. Their Approximate Composition and Certain Spectroscopic investigation bearing upon the hydrate problem (No. 60), Carnegie Institution of Washington: Baltimore, MD, (1907).

Pitzer, K.S. and Simonsont, J.M., Thermodynamics of Multicomponent, Miscible, Ionic Systems: Theory and Equations, Journal of Physical Chemistry, 90(13), 3005-3009 (1986).
Vicum. L.,Mazzotti, M. and Baldyga, J., Applying a Thermodynamic Model to the Non Stoichiometric Precipitation of Barium Sulfate, Chemical Engineering \& Technology, 26(3), 325-333 (2003).

Zafarani-Moattar, M.T. and Sardroodi, J.J., Isopiestic and Volumetric Study of $\mathrm{CuCl} 2+$ Ethanol at $25^{\circ} \mathrm{C}$, Journal of Chemical \& Engineering Data, 48(2), 308-313 (2003).

Osborne, N. S., Heat of fusion of ice. A revision, J. Res. Natl. Bur. Stand, 23, 643-646 (1939).

Osborne, N. S., Stimson, H. F., and Ginnings, D. $\mathrm{C}$., Measurements of heat capacity and heat of vaporization of water in the range 0 to $100{ }^{\circ} \mathrm{C}, \mathrm{J}$. Res. Natl. Bur. Stand, 23, 197-260 (1939).

Pitzer, K. S., and Silvester, L. F., Thermodynamics of electrolytes. VI. Weak electrolytes including $\mathrm{H}_{3} \mathrm{PO}_{4}$, Journal of Solution Chemistry, 5, 269-277 (1976).

Pitzer, K. S. and Silvester, L. F., Thermodynamics of Geothermal Brines I. Thermodynamic Properties of Vapor-Saturated $\mathrm{NaCl}(\mathrm{aq})$ Solutions From 0 $3 \mathrm{OO}^{\circ} \mathrm{C}$, Lawrence Berkeley Laboratory Report, (1976).

Platford, R. F., Thermodynamics of Aqueous Solutions of Orthophosphoric Acid from the Freezing Point to $298.15^{\circ} \mathrm{K}$, Journal of Solution Chemistry, 4(7), 591-598 (1975).

Randall, M., Methods of calculation of activity coefficients, Transactions of the Faraday Society, 23, 502-507 (1927).

Sippola H., and Taskinen P., Thermodynamic Properties of Aqueous Sulfuric Acid, Journal of Chemical \& Engineering Data, 59(8), 2389-2407 (2014)

Sippola, H., Critical Evaluation of the Second Dissociation Constants for Aqueous Sulfuric Acid over a Wide Temperature Range, Journal of Chemical \& Engineering Data, 58(11), 3009-3032 (2013).

Ge, X., Wang, X., Zhang, M., and Seetharaman, S., Correlation and Prediction of Activity and Osmotic Coefficients of Aqueous Electrolytes at $298.15 \mathrm{~K}$ by the Modified TCPC Model, Journal of Chemical \& Engineering Data, 52(2), 538-547 (2007).

Yang, H., Zhao, Z., Zeng, D., and Yin, R., Isopiestic Measurements of Water Activity for the $\mathrm{H}_{2} \mathrm{SO}_{4}$ $\mathrm{H}_{3} \mathrm{PO}_{4}-\mathrm{H}_{2} \mathrm{O}$ System at $298.15 \mathrm{~K}$, Journal of Solution Chemistry, 45(11), 1580-1587 (2016). 